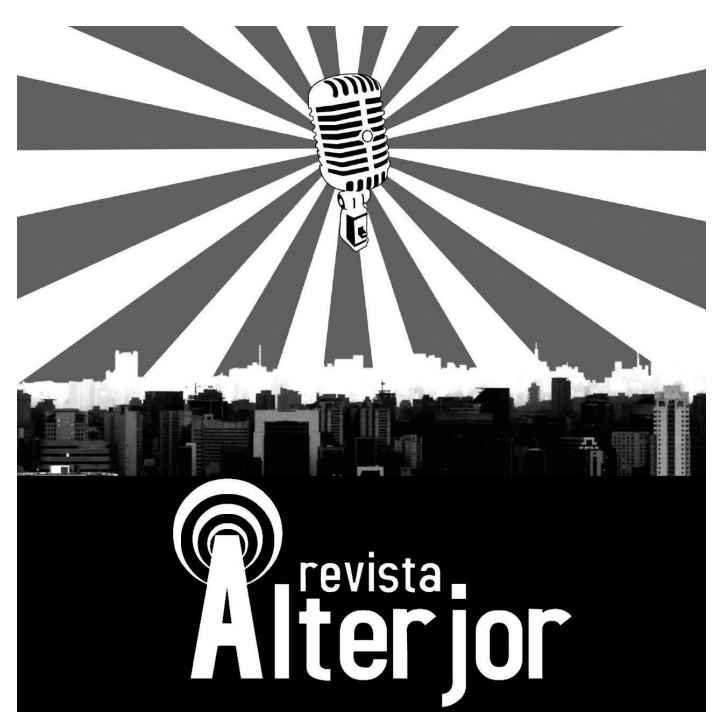

\title{
IMPRENSA NEGRA E DIVERSIDADE: PROGRAMA DIVERSIDADE EM CIÊNCIA DA RÁDIO USP
}

\author{
Jefferson Monteiro ${ }^{1}$ \\ Wilton Garcia ${ }^{2}$
}

RESUMO: O presente texto aborda o Programa Diversidade em Ciência da Rádio USP (93.7), ao considerar a discussão a respeito do racismo no jornalismo atual. $O$ procedimento metodológico (indutivo-dedutivo) contempla três ações: leitura, entrevista e escrita. Estudos contemporâneos do jornalismo fundamentam esta pesquisa. O jornalismo alternativo cumpre o papel de mediação entre diversas vozes excluídas.

PALAVRAS-CHAVE: Jornalismo. Etnia. Raça. Programa Diversidade em Ciência.

ABSTRACT: The present text addresses the Radio USP Diversity in Science Program (93.7), when considering the discussion about racism in journalism today. The methodological procedure (inductive-deductive) includes three actions: reading, interviewing and writing. Contemporary studies of journalism support this research. The alternative journalism plays the role of mediation between several excluded voices.

KEYWORDS: Jornalism. Ethyni. Race. Diversity in Cience Program.

\footnotetext{
${ }^{1}$ Especialização em Gestão de Conteúdo em Comunicação Jornalismo pela Universidade Metodista UMESP e Graduação em Gestão Comercial pela Fatec Itaquaquecetuba. E-mail: jefferson.montesan33@gmail.com.br

Professor da Fatec Itaquaquecetuba, Doutor em Comunicação pela USP, e-mail: wilton.garcia@fatec.sp.gov.br
}

\section{Revista ALTERJOR}

Grupo de Estudos Alterjor: Jornalismo Popular e Alternativo (ECA-USP)

Ano 11 - Volume 02 - Edição 24 - Julho-Dezembro de 2021

Av. Professor Lúcio Martins Rodrigues, 443, Cidade Universitária, São Paulo, CEP: 05508-020 


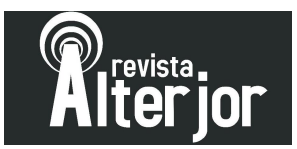

Talvez os guerreiros não nasçam prontos porque seria uma covardia do destino tirar da gente o prazer de ser um.

Madeleine Lockso Jornalista da rede Jovem Pan

O jornalismo traz uma característica fundamental de expor percepções em escala global, informando a realidade. Com o advento da internet, empresas jornalísticas estão modificando o modus operandi, bem como habilitando/preparando o novo jornalista que lida com uma nova audiência. Essa última absorve e produz conteúdo, de modo intenso.

O espaço de convergência criado pela internet e alimentado pelas redes sociais estimula maior liberdade de expressão e menores jogos de interesse pessoais. Isso se torna uma perspectiva favorável para que as práticas proeminentes abram lugar ao fortalecimento de um jornalismo com maior sintonia com o público. Para o professor Muniz Sodré (2008), pode-se trocar de suporte técnico, pode mesmo existir a complementação dos suportes (papel e eletrônico), mas continua o jornalismo impelido, como forma moderna e democrática da comunicação, pela ideologia humanista que garante a cidadania.

Sem o controle exclusivo da informação, as empresas jornalísticas se adequam à comunicação colaborativa, sendo essa medida a garantia da própria sobrevivência de um jornalismo em consonância com as demandas sociais no Brasil. O processo de readaptação das práticas jornalísticas deve contemplar a eficiência do fazer jornalístico no ambiente digital. A interatividade proposta deve ter critérios definidos a garantir integridade e objetividade, para que essa dinâmica, em constante mutação, seja bemsucedida.

Sob outra perspectiva, o jornalismo deve ficar atento às armadilhas criadas a partir desses tempos instantâneos, cuja produção de notícias não se restringe aos grandes veículos comunicacionais. E as notícias podem ser realizadas ou manipuladas nesses espaços vorazes, que se tornaram as redes sociais (BUCCI, 2000). Hoje, estudar o jornalismo requer um cuidado ético, técnico e estilístico para se promover a divulgação da mensagem (OLIVEIRA, 2016).

\section{Revista ALTERJOR}

Grupo de Estudos Alterjor: Jornalismo Popular e Alternativo (ECA-USP)

Ano 11 - Volume 02 - Edição 24 - Julho-Dezembro de 2021 Av. Professor Lúcio Martins Rodrigues, 443, Cidade Universitária, São Paulo, CEP: 05508-020 


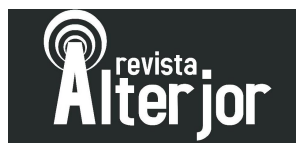

Todavia, o jornalismo pode ser mais autêntico no trato profissional. Seria a certeza do que está sendo exposto, inclusive a origem de suas fontes. O trânsito de informações aguça o interesse em futuras pesquisas no campo da comunicação, em especial no jornalismo. Os estudos contemporâneos sobre o jornalismo (BUCCI, 2000; FERREIRA, 2004, 2018; OLIVEIRA, 2016; SODRÉ, 2002, 2008) destacam-se como área profissional que possui um vasto repertório de apresentação e estudo.

O sistema de comunicação de massas não é somente jornalismo, aliás, o jornalismo ocupa uma parte pequena neste sistema. Esta é a segunda imprecisão das teorias da comunicação ao analisar o fenômeno do jornalismo, particularmente do seu papel construtor de visões ideológicas. Ao observarmos as mídias contemporâneas - televisão, rádio, meios impressos, internet - veremos que o jornalismo é uma parte ínfima. O que predomina são produtos de entretenimento (shows, variedades, ficção, entre outros) e 3 publicidade e propaganda. Portanto, o jornalismo ocupa uma parte minoritária neste arcabouço maior que é o sistema de comunicação massivo (OLIVEIRA, 2016, p. 2).

Essas questões no campo da comunicação, em particular o jornalismo, devem envolver a ideia de diversidade, sobretudo no Brasil, pois há uma mistura de etnia/raça aliada a gênero e/ou orientação sexual que diversifica a sociedade cada vez mais. "Para escrever sobre jornalismo, é fundamental alguma experiência de jornalismo, pelo menos como alguém que mergulha numa redação, no ambiente de uma televisão, etc. E para essa reflexão teórica vir desde dentro, tem que se aceitar a mídia” (SODRÉ, 2002, s/p.).

Dar voz aos dois lados de uma mesma história quando há dois lados que nela se enfrentam, é uma exigência ao mesmo tempo ética e técnica do jornalismo. Procurar a verdade dos fatos é um imperativo ético - e também o objetivo de toda a técnica jornalística (BUCCI, 2000, p. 50).

Longe de "dar voz", interessa gerar condições de participação de qualquer interessado. No jornalismo contemporâneo, mais especificamente na modalidade jornalismo de entrevista (com ações opinativas), Diversidade em Ciência ocupa uma lacuna vigorosa na mídia tradicional. Ou seja, não interessa a diversidade ao capital. A divulgação cientifica evoca algo mais presente na mídia e pouco vinculada no rádio.

\section{Revista ALTERJOR}

Grupo de Estudos Alterjor: Jornalismo Popular e Alternativo (ECA-USP)

Ano 11 - Volume 02 - Edição 24 - Julho-Dezembro de 2021 Av. Professor Lúcio Martins Rodrigues, 443, Cidade Universitária, São Paulo, CEP: 05508-020 
um projeto que repensa a divulgação científica ao trazer esse conceito para campos que muitas vezes não são vistos como ciência, no caso das pesquisas sobre diversidades e direitos humanos. Sinto que estou estimulando um novo paradigma, o das "ciências das diversidades". Se está mudando as realidades? Não sei. Na verdade, nem estou preocupado com isso. Sei que o Diversidade em Ciência é um instrumental que está aí, sendo disponibilizado. Faço e pronto. Se alguém quiser aproveitar esse instrumental será ótimo. Se não, que fique para o entendimento, pelo menos, da nossa contemporaneidade em pesquisas históricas do futuro (FERREIRA, 2018, p. 14).

Portanto, esse tipo de pesquisa sobre a diversidade no jornalismo apresenta ao público diferentes fenômenos sociais envolvendo questões complexas de etnia/raça, gênero, orientações sexuais, religião, classe social etc. O Programa Diversidade em Ciência da Rádio USP (93.7) cumpre o papel na difusão do diversus (diferentes versões), mediante a propagação e estimulo de novas descobertas que acena a diversidade.

\section{Imprensa negra}

A sociedade brasileira constitui-se de diferentes grupos étnico-raciais que, em termos culturais, é reconhecida como uma das mais criativas do mundo. No entanto, sua história é marcada por desigualdades e discriminações, especificamente contra negros e indígenas, trazendo dificuldades aos descendentes. São pessoas que, ainda hoje, sofrem estigmas sociais afetando e interferindo seus desenvolvimentos econômico, político e social.

Basta lembrar que tal sociedade foi constituída sob um formato em que a predominância de determinados grupos, numa estrutura já estabelecida, seria total e absoluta. Ou seja, a elite brasileira foi concebida sobre um regime escravagista, que em séculos de escravidão deixaram marcas profundas, tendo a discriminação, o preconceito, o racismo, a desigualdade e a injustiça como resquícios daquele período.

A elite branca brasileira já tinha em sua própria sociedade os elementos necessários para forjar sua ideologia racial. Tinha aprendido desde o período colonial a ver os negros como inferiores. Tinha também aprendido abrir exceções para alguns indivíduos negros ou mulatos (VIOTTI, 1998, p. 233-234).

\section{Revista ALTERJOR}

Grupo de Estudos Alterjor: Jornalismo Popular e Alternativo (ECA-USP)

Ano 11 - Volume 02 - Edição 24 - Julho-Dezembro de 2021 Av. Professor Lúcio Martins Rodrigues, 443, Cidade Universitária, São Paulo, CEP: 05508-020 


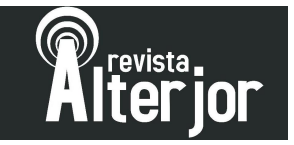

A cultura da diferença persiste na nossa sociedade cuja dinâmica de exclusão/inclusão evidencia a falésia societária e cria obstáculos. Historicamente, isso dificulta os caminhos para que os afrodescendentes possam se apropriar e usufruir de direitos de cidadania.

Em meio a essas fragmentações surgem as ocasiões para que sejam traçadas representações sociais. E diferentes perspectivas devem ser reconhecidas tanto nas manifestações produzidas pelos movimentos negros ou nas discussões acadêmicas da educação formal, quanto na sociedade. As diferentes explanações em disputa fundamentam-se em modos divergentes de situar as relações etno-raciais no Brasil. Essas representações vinculam-se, diretamente, às formas de observar o papel do racismo nas trajetórias das relações entre negros e brancos, bem como às identidades fragmentadas por distintas experiências.

Nesse sentido, a temática da democracia racial (tão exaltada), divulgada e pouco aplicada nessa sociedade, é colocada em xeque. Com isso, surgem discursos e representações na sociedade acerca de questões etno-raciais. Seja nas esferas pública ou privada, essas representações ganham novos contornos ampliando a noção de sujeito.

A discussão a respeito das ações afirmativas e a concepção de discursos favoráveis ou contrários às essas medidas, especialmente àquelas com enfoque na população negra, gera impactos, apresentando recursos para apreender as discrepâncias. Consensos e /ou dissensos são tecidos através das ações societárias dos grupos mobilizados e nas transformações sociais anunciam a diversidade. Para Ferreira (2004, p. 40). "não se pode perder a consciência, visto que esta é uma tese que devido sua persistência na cabeça de muitos brasileiros, permitindo que qualquer discriminação ocorra de modo inconsciente".

Algumas situações nem sempre podem ser identificadas como ato de discriminação. A instauração do sistema escravista, mais do que representar hierarquia ou uma ordem social, identificava-se como relação de poder, no qual serviu e ainda tem servido, com grande efetividade, para definir a falsa ideia de supremacia em contraponto aos negros. Mesmo após o seu fim, a escravidão pouco serviu para pôr fim a designação da pessoa humana baseada na cor da pele.

\section{Revista ALTERJOR}

Grupo de Estudos Alterjor: Jornalismo Popular e Alternativo (ECA-USP)

Ano 11 - Volume 02 - Edição 24 - Julho-Dezembro de 2021 Av. Professor Lúcio Martins Rodrigues, 443, Cidade Universitária, São Paulo, CEP: 05508-020 


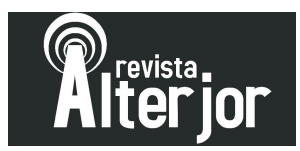

Para ser racista, é preciso colocar como postulado fundamental a crença na existência de "raças" hierarquizadas dentro da espécie humana. Ou seja, se cientificamente a realidade da raça é contestada, política e ideologicamente esse conceito é muito significativo, pois funciona como uma categoria de dominação e exclusão nas sociedades multirraciais contemporâneas observáveis (MUNANGA, 2009, p. 15).

A sociedade, ao fechar os olhos e sustentar um discurso de tom insolvente, encoberto sobre a cortina de falsa democracia racial, deixa evidente uma tentativa esdruxula de esconder as tensas relações etno-raciais, que se massificam diariamente. Isso reforça, sim, uma ideologia de pensamento obsoleto acerca da inferioridade dos afrodescendentes, ao impor mais obstáculos para o reconhecimento e a afirmação da identidade negra, haja vista que a imagem propagada seria sempre carregada de estigmas equivocados.

Com isso, a reprodução midiática de discursos estereotipados acerca dos afrodescendentes e a valorização da cultura dominante atuam equivocadamente na formação de uma sociedade racista e intolerante. Esse tipo de pensamento fica explicito na fala de D’adesky (2001, p. 93-94): “a mídia não somente atualiza a distância que separava, na escravidão, a elite do povo, mas nega, com seu exclusivismo, as identidades culturais afro-brasileiras e indígenas, as quais não tem acesso em pé de igualdade, as programações televisivas e radiofônicas".

Isso se reflete em vários meios, como no jornalismo, em que o número de negros nas redações, atrás das bancadas e no mercado publicitário é inexpressivo. Há tempos os negros buscam demonstrar a sua capacidade de participação na transformação da sociedade, seja ela cultural, política ou social. No decorrer dos anos, houve uma grande transformação com a implantação de políticas públicas voltadas à comunidade negra, como as cotas nas Universidades, fortalecimento da cultura negra (musical, estética, empoderamento entre outras).

Essa ideia é reforçada por Munanga (2012, p. 11):

De fato, a cultura brasileira no plural e sua identidade nacional foram modeladas pelos aportes da população negra. Estas contribuições culturais precisam ser resgatadas positivamente, desconstruindo imagens negativas que fizeram delas e substituindo-as pelas novas imagens positivamente reconstruída.

\section{Revista ALTERJOR}

Grupo de Estudos Alterjor: Jornalismo Popular e Alternativo (ECA-USP)

Ano 11 - Volume 02 - Edição 24 - Julho-Dezembro de 2021 Av. Professor Lúcio Martins Rodrigues, 443, Cidade Universitária, São Paulo, CEP: 05508-020 
Embora algumas políticas atenuantes não auxiliam na pauta das questões raciais do país. Esse tipo de política serve de aporte para uma discussão e se faz necessária; embora esteja atrasa há anos. Nesse sentido, a pauta da discriminação racial defendida pelos movimentos negros conseguiu adesão e o apoio do Sindicato dos Jornalistas do Estado de São Paulo (SJSP- http://www.sjsp.org.br), sendo o primeiro sindicato a combater a discriminação no jornalismo.

Vale registrar que a Comissão de Jornalistas pela Igualdade Racial (Cojira) surgiu a partir da mobilização dos profissionais da comunicação e assumiram o compromisso na defesa dos princípios da cidadania, da ética, na valorização da diversidade e oportunidades em favor da igualdade racial. Essa Comissão ganhou força e, atualmente, está presente em sete estados brasileiros e no Distrito Federal. Seu objetivo maior é garantir um mercado de trabalho menos excludente com um jornalismo mais sensíveis às questões sociais.

A imprensa tem papel fundamental para a construção estratégica das narrativas do cotidiano. É através dela que nos inteiramos de acontecimentos globais, adquirimos informações sobre fatos ocorridos nas sociedades, acontecimentos políticos a respeito de comportamento e consumo etc. Sem dúvida, isso ganha contornos de complexidade diante de uma sociedade que ainda acredita, ou finge em crer, na existência de uma democracia racial.

\begin{abstract}
A maior parte dos profissionais que compõe a imprensa é branca, e a cobertura da mídia tradicional, fomenta estereótipos que marginalizam e trazem uma imagem de subalternidade, condição de inferioridade e carência, aos afrodescendentes, incrementando a figura de indivíduos cuja natureza precisa ser melhorada ou corrigida. Em uma sociedade como a brasileira, de herança escravocrata, pessoas negras vão experenciar racismo do lugar de quem é objeto dessa opressão, do lugar que restringe oportunidades por conta desse sistema de opressão. Pessoas brancas vão experenciar do lugar de quem se beneficia dessa mesma opressão. Logo ambos os grupos podem e devem discutir essas questões, mas falaram de lugares distintos (RIBEIRO, 2017, p. 63).
\end{abstract}

Dessa forma, os jornais da imprensa negra surgiram com iniciativa profissional no intuito de criar visibilidade às diversas ações da população negra, sejam elas culturais

\title{
Revista ALTERJOR
}

Grupo de Estudos Alterjor: Jornalismo Popular e Alternativo (ECA-USP)

Ano 11 - Volume 02 - Edição 24 - Julho-Dezembro de 2021 Av. Professor Lúcio Martins Rodrigues, 443, Cidade Universitária, São Paulo, CEP: 05508-020 


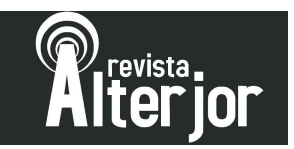

esportivas e educacionais, tornando-se mais um instrumento de combate contra o preconceito. Tal discurso alinha-se ao silogismo de Sodré (2008, s/p.), “o jornalismo, no Brasil e no resto do mundo, reflete as questões públicas decisivas para os rumos da Nação".

Portanto, vale mediar os fatores que impactam o papel da imprensa negra capaz de se debruçar sobre fatos para além de desigualdade econômica, injustiça social, entre outros. Consequentemente, potenciais inflexões não podem suprimir a evidência de que a imprensa brasileira jamais deixou de estar presente, como parte primordial, nas causas que auxiliaram o país a construir sua face. Destacam-se enfrentamentos de um programa de rádio universitário que tange a diversidade no país.

O Diversidade em Ciência é um espaço em que as diversidades étnicas; de identidades sexuais, de gêneros, de faixa etária e tantas outras estão presentes na bancada dos entrevistados. Tanto nas temáticas como na característica das pessoas. No caso de pesquisadores/cientistas essa preocupação é redobrada, considerando que percebo no jornalismo hegemônico que são pautadas muito mais pessoas brancas na academia para que possam falar sobre as suas produções. Penso que sujeitos pensantes negros; LGBTI+ e vários outros devam poder falar por si mesmos sem o filtro da branquitude. O mesmo acontece com os militantes sociais que são entrevistados. Portanto, o Diversidade em Ciência tem presença de muitos pesquisadores/cientistas e militantes não-brancos (FERREIRA, 2018, p. 13).

Por certo, uma das características marcantes da imprensa negra é congregar os afrodescendentes em um levante que traz uma postura de colaboração e solidariedade, ao empoderar a luta contra qualquer complexo de inferioridade. Nesse aspecto, procuram instigar os afrodescendentes intelectualmente para (re)ocupar seu lugar na sociedade. Por certo, a ação desses periódicos configura-se como ato de luta política, articulando a contemporaneidade.

\section{Programa Diversidade em Ciência}

O programa Diversidade em Ciência vai ao ar às segundas-feiras, das 13 às 14 horas; com reapresentações nas terças-feiras, das 2 às 3 horas e aos sábados, das 14 às 15

\section{Revista ALTERJOR}

Grupo de Estudos Alterjor: Jornalismo Popular e Alternativo (ECA-USP)

Ano 11 - Volume 02 - Edição 24 - Julho-Dezembro de 2021 Av. Professor Lúcio Martins Rodrigues, 443, Cidade Universitária, São Paulo, CEP: 05508-020 


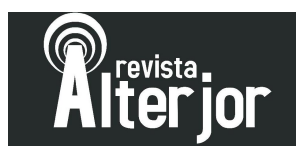

horas. Foi concebido e apresentado pelo jornalista e professor da Escola de Comunicação e Artes da Universidade de São Paulo Ricardo Alexino Ferreira (2004, 2018).

Como veículo de comunicação, a Rádio USP FM é uma emissora educativa, fundada em 1977. Já a Rádio USP Ribeirão (107.9), desde 2004, integra a rede de emissora universitária da USP. Esse compromisso educativo relaciona informação, cultura e entretenimento. Do ponto de vista jornalístico, a grade de atrações da rádio reúne enorme variedade de estilos musicais: do popular ao erudito. $\mathrm{O}$ foco dos debates dessa emissora gira em torno da divulgação de atividades acadêmicas, culturais, científicas e tecnológicas.

O enfoque na diversidade fica identificada logo em seu slogan: Discriminação é falta de conhecimento. Esse chamamento nos leva a uma reflexão, pois esse slogan convoca o debate e fomenta diálogos. Também, outra característica marcante do programa, é tema de abertura com a música Tchori Tchori do grupo indígena Jabutis de Rondônia, e interpretada por Marlui Miranda.

O formato jornalístico de entrevista aborda pesquisas científicas sobre relações étnico-sociais e diversidades desenvolvidas na Universidade de São Paulo e em outras Instituições de Ensino Superior (IES). Nos debates, questões étnicas, de gênero, orientações sexuais, de identidade etária, direitos humanos, entre outros assuntos, são realizados semanalmente.

Por possuir uma estrutura básica, o programa trilha sempre o enredo contando com pequenas variações, dividido em três blocos segue o seguinte roteiro: começa com a vinheta de abertura, apresentação do entrevistado e o tema abordado no dia. Na sequência vem à entrevista, ambientada por músicas escolhidas pelo convidado e a seguir vinheta chamando o intervalo.

Outra característica peculiar do programa é a trilha sonora de cada edição, que fica a cargo dos convidados as inserções musicais, que enfatizam a abordagem da conversa. Isso ambienta o programa em determinado assunto que ganha singularidade. Por ter essas características, acompanhadas de uma linguagem formal, o Diversidade em Ciência é uma vertente da divulgação cientifica, um canal de conexões de ideias impulsionada pelo rádio.

\section{Revista ALTERJOR}

Grupo de Estudos Alterjor: Jornalismo Popular e Alternativo (ECA-USP)

Ano 11 - Volume 02 - Edição 24 - Julho-Dezembro de 2021 Av. Professor Lúcio Martins Rodrigues, 443, Cidade Universitária, São Paulo, CEP: 05508-020 
O agendamento das temáticas das diversidades está presente no cotidiano; na política; nos movimentos sociais e em outros espaços. A proposta do Diversidade em Ciência é levar ao ar, em alguns aspectos, a produção científica nessa temática e dos direitos humanos nas mais diferentes áreas do conhecimento. Mas o programa também leva ao ar o agendamento dos movimentos sociais. Ele escuta os sujeitos desse processo. Não considero que exista dificuldade nesse aspecto, mas é uma forma do rádio também agendar essa temática para demais grupos sociais e trazer com mais intensidade esse debate. Em relação à recepção desse trabalho para os ouvintes, não tenho dados, considerando que ainda não foi elaborada nenhuma pesquisa de audiência (FERREIRA, 2018, p. 12).

Ao abordar a divulgação cientifica dos direitos humanos e das ciências da diversidade, o programa Diversidade em Ciência - além de produzir discussões/reflexões acerca dos recortes sobre as pesquisas cientificas - socializa o pensamento científico, pois sua proposta de integrar ciência, diversidades e jornalismo, explorar e contextualiza as conexões de ideias. Isso incrementa os projetos das áreas de ciências humanas e ciências sociais aplicadas, produzem pesquisas relevantes nos desenvolvimentos econômico e social do país.

Sobre o critério jornalístico, o entrevistado afirma:

O critério para o agendamento das entrevistas se dá pelo recorte dos temas pesquisados ou atuados, envolvendo as diversidades. Então, estou preocupado em entrevistar pesquisadores/cientistas que pesquisam o tema ou militantes dos grupos das diversidades. Esse é o critério. Penso as diversidades nos mais diferentes espectros. Trato das diversidades étnicas; identidades sexuais; gêneros; veganos e várias outras características. Uma preocupação que tenho é alternar as temáticas para que o ouvinte tenha acesso às mais diferentes realidades construídas e colocadas. O levantamento de pautas se dá na verificação constantes das pesquisas produzidas; nas redes sociais e em outros espaços. Porém, nos últimos anos tem surgido um processo interessante. Algumas pessoas estão se oferecendo para ser entrevistadas ou sugerindo nomes (FERREIRA, 2018, p. 12).

Essa curadoria de convidados demonstra o rigoroso critério profissional. Os agendamentos do programa ampliam o debate sobre a diversidade, como emergente

\section{Revista ALTERJOR}

Grupo de Estudos Alterjor: Jornalismo Popular e Alternativo (ECA-USP)

Ano 11 - Volume 02 - Edição 24 - Julho-Dezembro de 2021 Av. Professor Lúcio Martins Rodrigues, 443, Cidade Universitária, São Paulo, CEP: 05508-020 


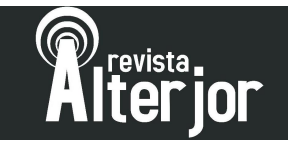

campo de estudo, envolvendo a percepção ampla da comunicação. O que aprofunda os fenômenos midiáticos.

A comunicação alternativa desse Programa revela estratégias que amparam a defesa da diversidade. Conforme Canclini, (1999, p. 16), "a diversidade na comunicação midiática a que nos referimos é a multiplicidade de expressões, a despeito da desigualdade, que se refere ao não-benefício a todos da expansão midiática e econômica que abranja as diferenças".

A questão da diversidade seja social, cultural ou identitária possui a peculiaridade de invocar os diversos discursos de pertencimento, que se encontram nas mídias (jornais, televisão e internet e outros). As práticas discursivas, nessa propagação, podem melhorar as relações sociais. Essas relações estão propensas aos estudos da mídia e da divulgação da ciência, podendo ser atreladas essas áreas de extensão universitária. O que melhora a extensa percepção correlativa da comunicação, levando o rádio como espaço de interlocução.

O rádio é, por definição, um meio dinâmico. Está presente lá, onde a notícia acontece, transmitindo-a em tempo real para o ouvinte (...). Neste século XXI de tantas tecnologias e, por vezes, de poucas humanidades, constitui-se por natureza, e cada vez mais, em um instrumento de diálogo, atento às demandas do público e cioso por dizer o que as pessoas necessitam e desejam ouvir em seu dia a dia. Tudo de forma muito simples, clara, direta e objetiva. (FERRARETTO, 2014, p. 13)

Por ser um dos mais antigos meios de comunicação, o rádio tem seu lugar de destaque mesmo com o advento das novas tecnologias da cultura digital. Ao longo do tempo, o rádio foi sendo modificado para acompanhar as novas tendências, cuja mobilidade da radiodifusão, relacionada ao imediatismo, não se compara aos outros meios.

Pensar a diversidade no âmbito cientifico e tendo o rádio como canal direto de comunicação é abrir espaço para a pluralidade de ideias, conceitos, estilos e cenários. Segundo Ferreira (2018), cada pessoa está condicionada a pensar segundo suas condições de existência. O pensamento de cada um reflete o mundo em que o indivíduo conhece e

\section{Revista ALTERJOR}

Grupo de Estudos Alterjor: Jornalismo Popular e Alternativo (ECA-USP)

Ano 11 - Volume 02 - Edição 24 - Julho-Dezembro de 2021 Av. Professor Lúcio Martins Rodrigues, 443, Cidade Universitária, São Paulo, CEP: 05508-020 


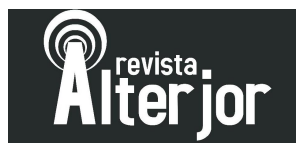

se insere, bem como suas vivências, privilégios, condições. Ou seja, tudo ecoa para a realidade.

Todo indivíduo que pertença à diversidade, em algum momento, vivencia alguma situação de preconceito/exclusão. Tendo em mente que, na sociedade contemporânea, a influência da mídia impressa e/ou digital é forte o bastante para contribuir com o desenvolvimento de ideias, reflexões e/ou pensamentos. E o aumento da (in)tolerância etno-racial dá margem às invisibilidades discursivas dos menos favorecidos, sobretudo os periféricos. Para Santos (2009, p. 43), “somos, hoje, quer queiramos ou não, obrigados a ver o outro, o diferente, não somente na sua diferença, mas, principalmente, reivindicando o direito à sua diferença e ao mesmo tempo a igualdade de direitos, aos direitos humanos".

\section{Considerações finais}

O Programa Diversidade em Ciência é um trabalho jornalístico de divulgação científica da Rádio USP $(93,7)$, contextualizando elementos conceituais, teóricos, políticos e práticos. Esses elementos reúnem circunstâncias providenciais para se avançar sobre a democracia racial, para além do lugar comum.

Como produção de conhecimento, o resultado da elaboração dessa pesquisa mostra que o rádio pode ser um eficiente divulgador de ciências, além de democratizar o pensamento científico e tecnológico, colocando-o de maneira acessível ao público e ligado ao cotidiano. Tal pensar permite autonomia, emancipação e independência com o viés intersubjetivo de Ser/Estar sujeito no mundo.

O caminho para superar injurias, discriminações, estereotipização ou estigmas é, sem dúvida, a produção do conhecimento. A realidade nos diferencia fomenta a necessidade de um diálogo aberto, sem imposições de força de qualquer lado. $\mathrm{O}$ modo dos grupos sociais se relacionarem ressaltam diferenças que nos constituem enquanto corpo social. Talvez, o primeiro passo contra a discriminação seria assumir o conjunto de existência, realidade e verdade. E o jornalismo alternativo cumpre o papel de mediação entre diversas vozes excluídas.

\section{Revista ALTERJOR}

Grupo de Estudos Alterjor: Jornalismo Popular e Alternativo (ECA-USP)

Ano 11 - Volume 02 - Edição 24 - Julho-Dezembro de 2021 Av. Professor Lúcio Martins Rodrigues, 443, Cidade Universitária, São Paulo, CEP: 05508-020 


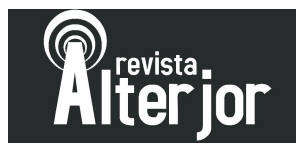

Refletir sobre a diversidade compõe o cotidiano de uma sociedade em desenvolvimento. E o formato jornalístico de entrevista, além de trabalhar - com a divulgação cientifica, os direitos humanos e as ciências das diversidades no rádio tornou-se um porta-voz para que pesquisadores/cientistas de diversas áreas do conhecimento, exponham os resultados de suas pesquisas, estimulando o pensamento crítico-reflexivo sobre diversidade, etnia-raça, identidades sexuais e de gêneros, entre outros temas.

$\mathrm{Na}$ contemporaneidade, reconhecer que somos diferentes não é o suficiente para combater os estereótipos e os estigmas criados, acerca das questões da diversidade, que estão presentes nos agendamentos políticos, sociais, midiáticos. Falar sobre diversidade não pode ser somente um exercício de perceber os diferentes, de tolerar, respeitar e admitir a diferença. Explicar essa diferença torna-se fundamental na construção estratégica de uma sociedade mais igualitária. As questões da diversidade, sejam como afirmação ou negação, trazem reflexões.

\section{REFERÊNCIAS}

BUCCI, E. Sobre ética e imprensa. São Paulo: Cia das Letras, 2000.

CANCLINI, N. G. Consumidores e cidadãos: conflitos multiculturais da globalização. Rio de Janeiro: UFRJ, 1999.

COJIRA-SP. Disponível em: https://cojira.wordpress.com/category/manifesto-cojirasp/ Acessado em: 20 jan 2018

D’ADESKY, J. Pluralismo étnico e multiculturismo: racismo e antirracismo no Brasil. Rio de Janeiro: Pallas, 2001.

FERRARETTO, L. A. Rádio: teoria e prática. SP: Summus, 2014.

FERREIRA, R. A. Entrevista sobre o programa de rádio Diversidade em Ciência da Rádio USP (93.7). REGIT, Fatec Itaquaquecetuba, v. 10, n. 2, p. 9-15, jul/dez 2018.

FERREIRA, R. A. Jornalismo especializado-jornalismo científico: análise crítica, estudo de casos e a construção de novos paradigmas e de um novo currículo disciplinar. Bauru: Faac-Unesp. Pesquisa Trienal. Mimeo. 2004.

GARCIA, W. Pensar as mídias alternativas. Observatório da Imprensa. ed. 996, São Paulo: Projor, 2018. Disponível em: <goo.gl/jjeiMb>. Acessado em: 25 jan 2021.

\section{Revista ALTERJOR}

Grupo de Estudos Alterjor: Jornalismo Popular e Alternativo (ECA-USP)

Ano 11 - Volume 02 - Edição 24 - Julho-Dezembro de 2021 Av. Professor Lúcio Martins Rodrigues, 443, Cidade Universitária, São Paulo, CEP: 05508-020 


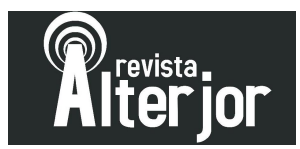

MUNANGA, K. Negritude e identidade negra ou afro descendente: um racismo ao avesso? Revista da ABPN, v. 4, n. 8, jul/out. 2012.

MUNANGA, K. Negritude: usos e sentidos. Belo Horizonte: Autêntica, 2009.

OLIVEIRA, D. Novos protagonismos midiáticos-culturais: a resistência a opressão da sociedade da informação. REGIT - Revista de Estudos de Gestão, Informação e Tecnologia v. 6, n. 2, p. 17-37, jul/dez 2016. Disponível em: <goo.gl/xL8Zmf>. Acessado em: 24 jan 2021.

RIBEIRO, D. O que é lugar de fala? Belo Horizonte: Letramento, 2017.

SANTOS, B. de S. Para além do pensamento abissal: das linhas globais a uma ecologia de saberes. In: SANTOS, B. S.; MENESES, M. P. (Org). Epistemologias do Sul. Coimbra: Almedina; CES, 2009, p. 23-71

SODRÉ, M. A mídia como forma de vida. Pesquisa Fapesp. Ed. 78, ago, 2002.

Disponível em: https://revistapesquisa.fapesp.br/a-forma-de-vida-da-midia/. Acessado em: 31 jan 2021.

SODRÉ, M. Viva o diploma: comunicação interna à lista eletrônica do Fórum Nacional de Professores de Jornalismo, jul./2008.

VIOTTI, E. Da monarquia à república: momentos decisivos. São Paulo. Editora UNESP, 1998. 